\title{
ER stress inhibitor attenuates hearing loss and hair cell death in $\mathrm{Cdh} 23^{\text {erl/erl }}$ mutant mice
}

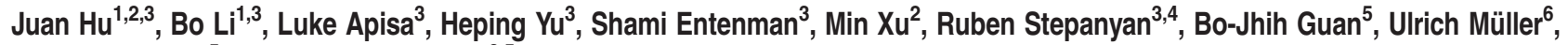 \\ Maria Hatzoglou ${ }^{5}$ and Qing Yin Zheng ${ }^{*, 3,5}$
}

Hearing loss is one of the most common sensory impairments in humans. Mouse mutant models helped us to better understand the mechanisms of hearing loss. Recently, we have discovered that the erlong (erl) mutation of the cadherin23 (Cdh23) gene leads to hearing loss due to hair cell apoptosis. In this study, we aimed to reveal the molecular pathways upstream to apoptosis in hair cells to exploit more effective therapeutics than an anti-apoptosis strategy. Our results suggest that endoplasmic reticulum (ER) stress is the earliest molecular event leading to the apoptosis of hair cells and hearing loss in erl mice. We also report that the ER stress inhibitor, Salubrinal (Sal), could delay the progression of hearing loss and preserve hair cells. Our results provide evidence that therapies targeting signaling pathways in ER stress development prevent hair cell apoptosis at an early stage and lead to better outcomes than those targeting downstream factors, such as tip-link degeneration and apoptosis.

Cell Death and Disease (2016) 7, e2485; doi:10.1038/cddis.2016.386; published online 24 November 2016

The cadherin $23(\mathrm{CDH} 23)$ protein is localized in the upper part of the tip link in hair cells, where it functions as a key component. ${ }^{1-3}$ In humans, Cdh23 mutations cause nonsyndromic autosomal recessive deafness (DFNB12) and Usher syndrome type 1D, USH1D, characterized by deafness associated with retinitis pigmentosa and vestibular dysfunction. ${ }^{4-6}$ In mice, Cdh23 mutations lead to hearing loss with or without vestibular dysfunction. ${ }^{7-9}$ Recently, we identified a novel point mutation (T208C) of Cdh23 and named this mutation erlong (erl). ${ }^{10}$ The Cdh23 ${ }^{\text {erl/erl }}$ mice (erl mice) proved to be animal models of DFNB12. Previously, we showed that hair cell apoptosis is one of the pathological mechanisms leading to hearing loss in this mutant. ${ }^{10}$ Here, we aimed to reveal that ER stress signaling is the upstream pathway leading to hair cell apoptosis in mice with the erl mutation, and we sought to find potential therapeutics.

The perturbation of endoplasmic reticulum (ER) homeostasis leads to the accumulation of unfolded or misfolded proteins in the ER lumen, resulting in ER stress. The unfolded protein response (UPR) is subsequently triggered to alleviate this stress and to restore ER homeostasis, promoting cell adaptation and survival. Conversely, if the stress is prolonged, or if the adaptive response fails, the apoptosis pathway will be initiated. ${ }^{11-13}$ The UPR is mediated through three ER transmembrane receptors: protein kinase RNA-like ER kinase (PERK); activating transcription factor-6 (ATF6); and inositolrequiring enzyme 1 (IRE1). ${ }^{11-14}$ Upstream of this network, the ER chaperone immunoglobulin-binding protein $(\mathrm{BiP})$ functions as a main regulator by dissociating from the PERK, ATF6 and IRE1 luminal domains and thus activating these effectors' stress responses. As a downstream signal, the CCAAT/ enhancer-binding protein-homologous protein $(\mathrm{CHOP})$ is considered to be a very sensitive indicator of ER stress conditions, and its induction mostly promotes cell death. ${ }^{11,13}$

A recent study of zebrafish mutants revealed that the Usher proteins, including $\mathrm{CDH} 23$, formed a complex and then preassembled at the ER. ${ }^{15}$ Defects in the Usher proteins disrupted the complex formation, induced the protein-trafficking defects, and finally triggered ER stress and apoptosis. Hence, blocking ER stress pro-apoptosis factors could reduce cell death in zebrafish mutants. ${ }^{15}$ Because the erl mutation affects Cdh23, the same gene that causes USH1D in humans, it is reasonable to speculate that the $\mathrm{ERL}-\mathrm{CDH} 23$ protein might endure defective trafficking, thus triggering ER stress and leading to hair cell apoptosis and hearing impairment in erl mutants. In the current study, we tested the expression of the $\mathrm{ER}$ chaperone $\mathrm{BiP}$ and the pro-apoptotic factor $\mathrm{CHOP}$ in the erl and control C57BL/6 J (B6) mouse cochleae. Our data show that ER stress and the UPR response were the underlying causes of apoptosis in the erl cochleae, with the PERK signaling being a contributor. More importantly, we report here that the small molecular compound of ER stress inhibitor Salubrinal (Sal) could slow down the progression of hearing loss and hair cell death in erl mice. These results offer a potential therapy for human DFNB12 and possibly protect the visual function of individuals with Usher syndrome.

\section{Results}

CDH23 partly failed to reach the top of hair bundles and were co-localized with $\mathrm{BiP}$ in the subapical regions of $\mathrm{OHCs}$ in erl mice. We measured the $\mathrm{CDH} 23$ distribution in

\footnotetext{
${ }^{1}$ Transformative Otology and Neuroscience Center, Binzhou Medical University, Yantai, Shandong, China; ${ }^{2}$ Department of Otorhinolaryngology-HNS, Second Affiliated Hospital, Xi'an Jiaotong University School of Medicine, Xi'an, Shaanxi, China; ${ }^{3}$ Department of Otolaryngology-HNS, Case Western Reserve University, Cleveland, OH, USA; ${ }^{4}$ Department of Neurosciences, Case Western Reserve University, Cleveland, OH, USA; ${ }^{5}$ Department of Genetics and Genome Sciences, Case Western Reserve University, Cleveland, OH, USA and ${ }^{6}$ Department of Molecular and Cellular Neuroscience, Dorris Neuroscience Center, The Scripps Research Institute, La Jolla, CA, USA ${ }^{*}$ Corresponding author: QY Zheng, Department of Otolaryngology-HNS, Case Western Reserve University, 11100 Euclid Ave, LKS 5045, Cleveland 44106, OH, USA. Tel: +1 216-844-3441; Fax: +1 216 844-7268; E-mail: qing.zheng@ case.edu Received 04.6.16; revised 19.10.16; accepted 24.10.16; Edited by A Verkhratsky
} 
a $\mathrm{CDH} 23$ DAPI
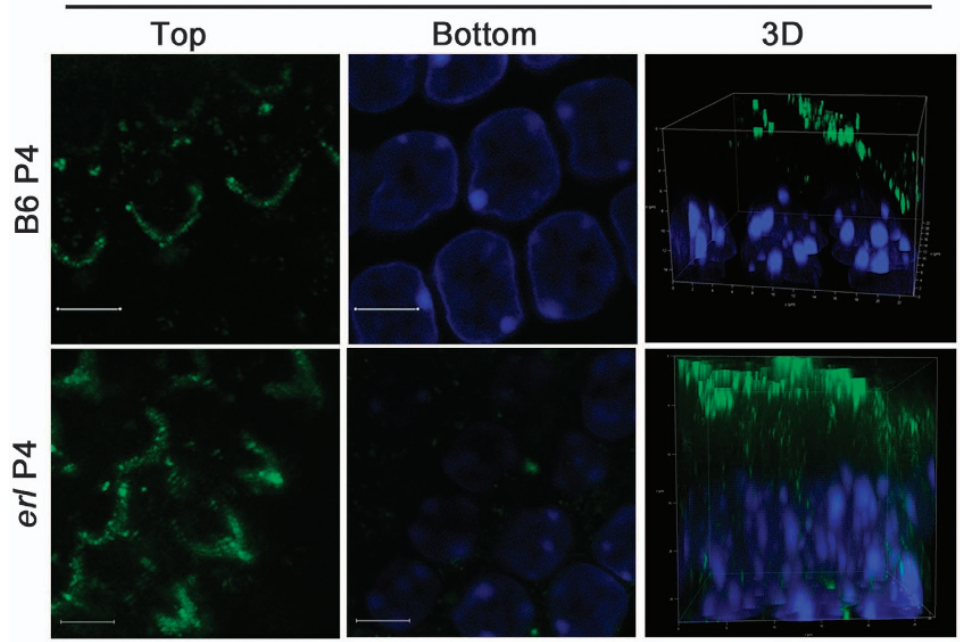

C
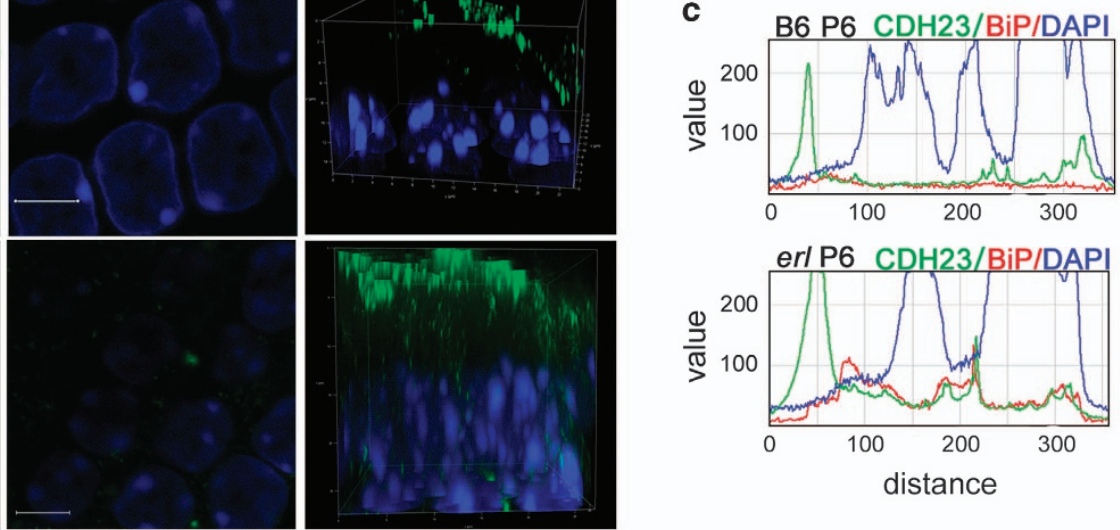

b
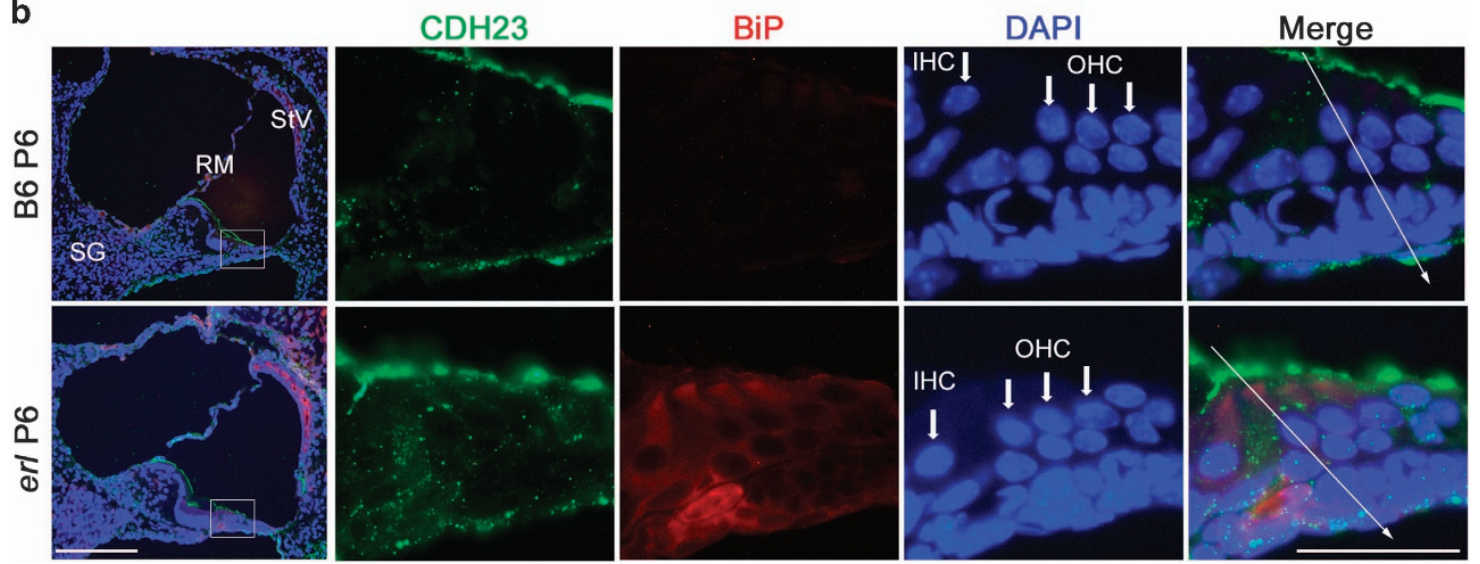

Figure $1 \mathrm{CDH} 23$ expression and co-localization with BiP in erl mouse cochleae. (a) Top and bottom confocal stack sections and 3D reconstruction of confocal images (x63) revealed the location of $\mathrm{CDH} 23$ in the B6 (voxel-size $512 \times 512 \times 0.045 \mu \mathrm{m}^{3}$ and total volume $23.2 \times 23.2 \times 14.9 \mu \mathrm{m}^{3}$ ) and erl (voxel-size $1024 \times 1024 \times 0.027 \mu \mathrm{m}^{3}$ and total volume $27.2 \times 27.2 \times 27.2 \mu \mathrm{m}^{3}$ ) OHCs at P4. In the B6 mice, $\mathrm{CDH} 23$ protein was specifically localized at the tip of stereocilia of OHCs. The erl mice OHCs showed a wide range of $\mathrm{CDH} 23$ expressions (from the stereocilia to the nucleus). Around the nuclei, no detectable $\mathrm{CDH} 23$ signal was found in $\mathrm{B} 6$ mice, while in erl mice, many spots of $\mathrm{CDH} 23$ signal was detected in this region ( $n=3$ mice per group). Scale bars, $5 \mu \mathrm{m}$. (b) The location and co-localization of BiP and CDH23 in the B6 and erl cochleae at P6. The B6 mice cochleae showed faint BiP signals and clear $\mathrm{CDH} 23$ signals, particularly on the tops of the OHCs. BiP was highly detected in the OHCs, SG, and StV of erl mice, and it was co-localized with $\mathrm{CDH} 23$ in the subapical regions of the OHCs ( $n=3$ mice per group). Scale bars, $50 \mu \mathrm{m}$ (left); $20 \mu \mathrm{m}$ (right). (c) The line charts show two-dimensional graphs of the raw fluorescence intensities of the white arrows drawn in the panels to the left, as analyzed by Image $\mathrm{J}$ software. The $X$-axis represents distance (pixels) along the line, and the $Y$-axis is the pixel intensity. The BiP signals were highly expressed in erl mice and partially overlapped with the $\mathrm{CDH} 23$ signals ( $n=3$ mice per group)

cochlear outer hair cells (OHCs) in erl mice and B6 mice. At P4, the CDH23 protein was specifically localized at the top of the $\mathrm{OHCs}$ in $\mathrm{B} 6$ mice, as revealed by confocal $3 \mathrm{D}$ images, indicating the localization of the tip links in hair bundle stereocilia (Figure 1a). In contrast, the $\mathrm{CDH} 23$ protein localized from the stereocilia to the nuclei of the OHCs in erl mice. Portions of the $\mathrm{CDH} 23$ proteins failed to reach the top of the hair bundles and remained in the $\mathrm{OHC}$ cytoplasm. Immunostaining showed that the ER chaperone BiP was more readily detected in almost the same region and co-localized with cytoplasmic $\mathrm{CDH} 23$ in the erl mouse $\mathrm{OHCs}$ at P6 (Figure 1b), whereas no specific BiP signaling was detectable in the cytoplasm of the B6 mouse OHCs. Line charts confirmed the higher expression of $\mathrm{BiP}$ and its co-localization with $\mathrm{CDH} 23$ in the erl $\mathrm{OHC}$ cytoplasm
(Figure 1c) when compared with the fluorescence intensity of $\mathrm{CDH} 23$ and $\mathrm{BiP}$.

The PERK arm of UPR was activated in the erl mouse cochleae. The ER stress marker BiP was upregulated in the erl mice inner ears, as compared with those of B6 mice. In the measurements of mRNA isolated from the erl mouse cochleae, BiP was upregulated at P12 but downregulated at P30 (Figure 2a). Immunostaining showed not only a greater expression of $\mathrm{BiP}$ in $\mathrm{OHCs}$ but also that $\mathrm{BiP}$ was expressed at higher levels in spiral ganglion (SG) cells and in stria vascularis (StV) in the erl cochleae at P6 and P12 (Figure $2 \mathrm{~b}$ and $\mathrm{c}$ ). Consistent with the confocal threedimensional (3D)_images, the BiP signals were mainly localized in the $\mathrm{OHC}$ cytoplasm and formed a hat-like pattern 

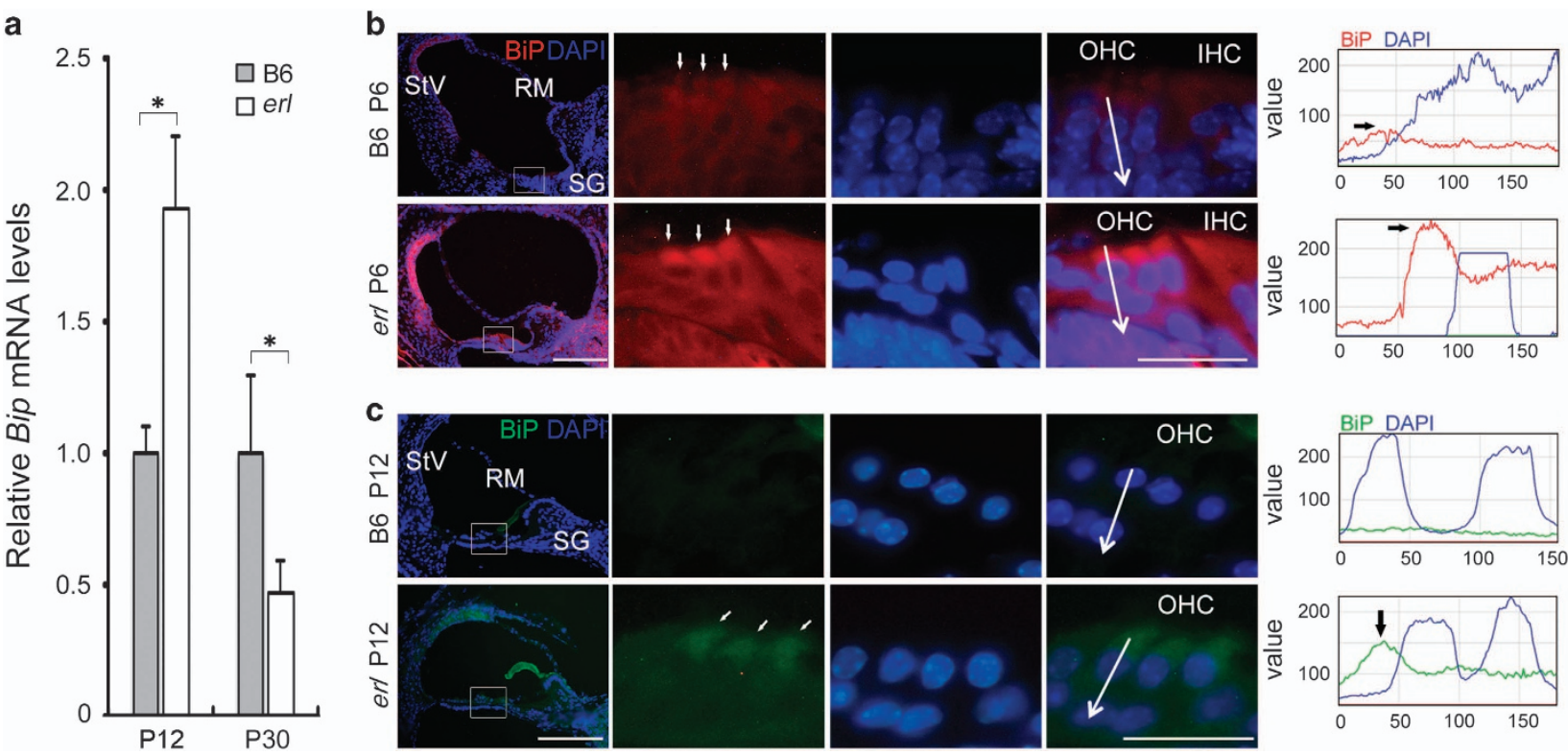

Figure 2 BiP expression in the B6 and erl mouse cochleae. (a) The Bip mRNA levels in the cochleae of the B6 and erl mice at P12 and P30. The Bip mRNA level was significantly higher in the erl mice at P12 but decreased at P30, compared with the B6 cochleae. The error bars represent S.E.M. ( ${ }^{*} P<0.05, n=3$ mice, $t$-test). (b,c) The BiP showed higher intensities in the StV, SG and especially OHCs of the erl mice, forming a hat-like pattern on the top of the OHCs' nuclei at P6 and P12. A line intensity analysis revealed that the BiP signals were expressed in the $\mathrm{OHC}$ area of the erl cochleae ( $n=4$ mice per group). Scale bars, $50 \mu \mathrm{m}$ (left); $20 \mu \mathrm{m}$ (right)

above the OHCs' nuclei (Figure $2 \mathrm{~b}$ and $\mathrm{c})$. ER stress effector PERK's kinase target, the phosphorylated alpha-subunit of the eukaryotic initiation factor (elF2a), also showed strong localization in the perinuclear regions of the $\mathrm{OHCs}$ in the erl cochleae (Figure 3).

Downstream of the PERK arm, the pro-apoptotic factor $\mathrm{CHOP}$ was also expressed at higher levels in the erl cochleae (Figure 4). At the mRNA level, Chop maintained a higher expression in the erl cochleae compared with $\mathrm{B} 6$ cochleae at P12 and P30 (Figure 4a). Immunostaining performed at the same age showed that $\mathrm{CHOP}$ was highly detected in the $\mathrm{OHCs}, \mathrm{SG}$ and StV of erl mice and was mainly detected in the perinuclear regions of $\mathrm{OHCs}$ (Figure $4 \mathrm{~b}$ and $\mathrm{c}$ ). However, a bare $\mathrm{CHOP}$ signal was present in $\mathrm{B} 6$ mouse cochleae.

\section{Disruption of the Chop gene protected hearing and OHCs} in erl mice. To further confirm the involvement of Chop in ER stress-induced apoptosis in erl mice, we used double-mutant mice containing the erl mutation in the Cdh23 gene and a disruption in the Chop gene. The inbred mice were obtained by crossing $\mathrm{Chop}^{-/-}$mice with $\mathrm{Cdh} 23^{\text {erl/erl }}$ mice. Nine genotypes of mice sharing the same genetic background

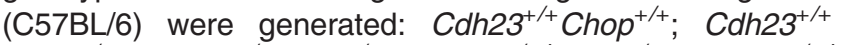

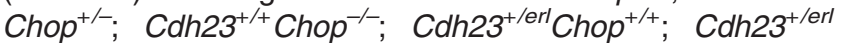
$\mathrm{Chop}^{+-}$; Cdh23 $3^{+/ \text {erl }} \mathrm{Chop}^{-/} ; \quad \mathrm{Cdh} 23^{\text {erlerl }} \mathrm{Chop}^{+/+}$; Cdh23 $3^{\text {erlerl }} \mathrm{Chop}^{+-}$; and Cdh23 $3^{\text {erlerl }}$ Chop $^{-1-}$. Supplementary Figure 1 shows the genotyping of the

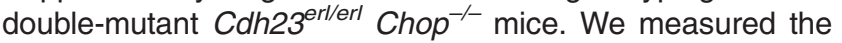
hearing and cytocochleograms of the $\mathrm{Cdh}_{2} 3^{\mathrm{erl} / \mathrm{erl}} \mathrm{Chop}^{-1}$; $\mathrm{erl}$ (Cdh23 $\left.3^{\text {erlerl }} \mathrm{Chop}^{+/+}\right)$; and $\mathrm{Chop}^{-/-}\left(\mathrm{Cdh}^{2} 3^{+/+} \mathrm{Chop}^{-/}\right)$mice. At 10 weeks, the auditory-evoked brainstem response (ABR) thresholds in the $\mathrm{Cdh}_{2} 3^{\text {erl/erl }} \mathrm{Chop}^{-/-}$double-mutant mice were significantly better than those in the erl mice
(Figure 5a). The surface preparation performed at the same age revealed less loss of $\mathrm{OHC}$ in the $\mathrm{Cdh}_{2} 3^{\text {erl/erl }} \mathrm{Chop}^{-/}$ double-mutant mice in comparison with $\mathrm{Cdh} 23^{\text {erl/erl }}$ mice. In the erl mice, several spots of $\mathrm{OHC}$ loss were exhibited in the basal and middle turns, and a few $\mathrm{OHC}$ losses were shown in the apical turns of the cochleae. However, in the $\mathrm{Cdh}_{2} 3^{\text {er//rl }} \mathrm{Chop}^{-1}$ double-mutant mice, no OHC loss was found in the entire length of the cochleae (Figure 5b). The quantitative study showed that the mean percentage of $\mathrm{OHC}$ loss in the $\mathrm{Cdh} 23^{\text {erl/erl }} \mathrm{Chop}^{-/-}$mice was significantly lower than that in the erl mice (Figure $5 \mathrm{c}$ ).

Sal prevented hearing loss in erl mice. After receiving corresponding treatments, the erlmice in the test, vehicle and control groups underwent $A B R$ and distortion product otoacoustic emission (DPOAE) testing at the same ages. The ABR thresholds in the test group were significantly lower than those in the vehicle and control groups in response to 16 (Figure $6 \mathrm{a}$ and b), 8 and $32 \mathrm{kHz}$ tone-burst and click stimuli (Supplementary Figure 2). No significant difference was found between the vehicle and control groups. The otoprotective effect was further confirmed by the higher DPOAE amplitudes. At 8 weeks, the DPOAE amplitudes in the test group were significantly greater at high frequencies (Supplementary Figure 3a). At 12 weeks, the test group showed much higher DPOAE amplitudes at almost all frequencies (Figure 6c). At 16 weeks, mice in all three groups showed lower DPOAE amplitudes, whereas the test group's amplitudes remained higher at low frequencies (Supplementary Figure 3b).

Sal protected against $\mathrm{OHC}$ death in erl mice. A cochlear surface preparation was performed on erl mice in the test, 

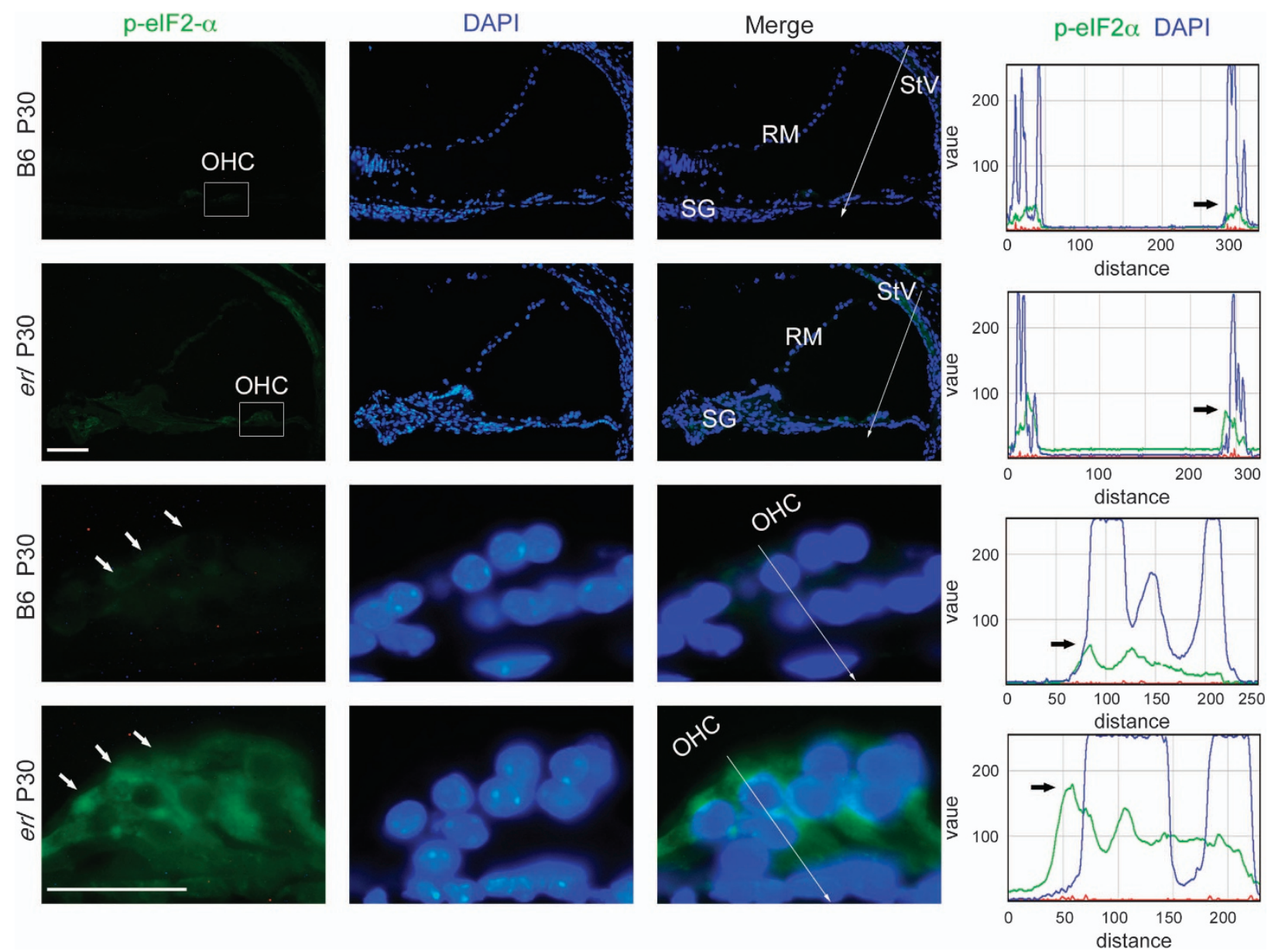

Figure 3 The elF2 $\alpha$ phosphorylation in the B6 and erl cochleae at P30. The immunefluorescence labeling of phospho-elF2 $\alpha$ showed strong cytoplasmic and perinuclear localization in the cochleae of the erl mice. The line intensity analysis along the arrow shown in the panels to the left revealed that the p-elF2 $\alpha$ signals were expressed in the OHC and stria vascularis (StV) areas and were strongly detected around the nuclei in the erl cochleae ( $n=3$ mice per group). Scale bars, $50 \mu \mathrm{m}$ (upper); $20 \mu \mathrm{m}$ (lower)
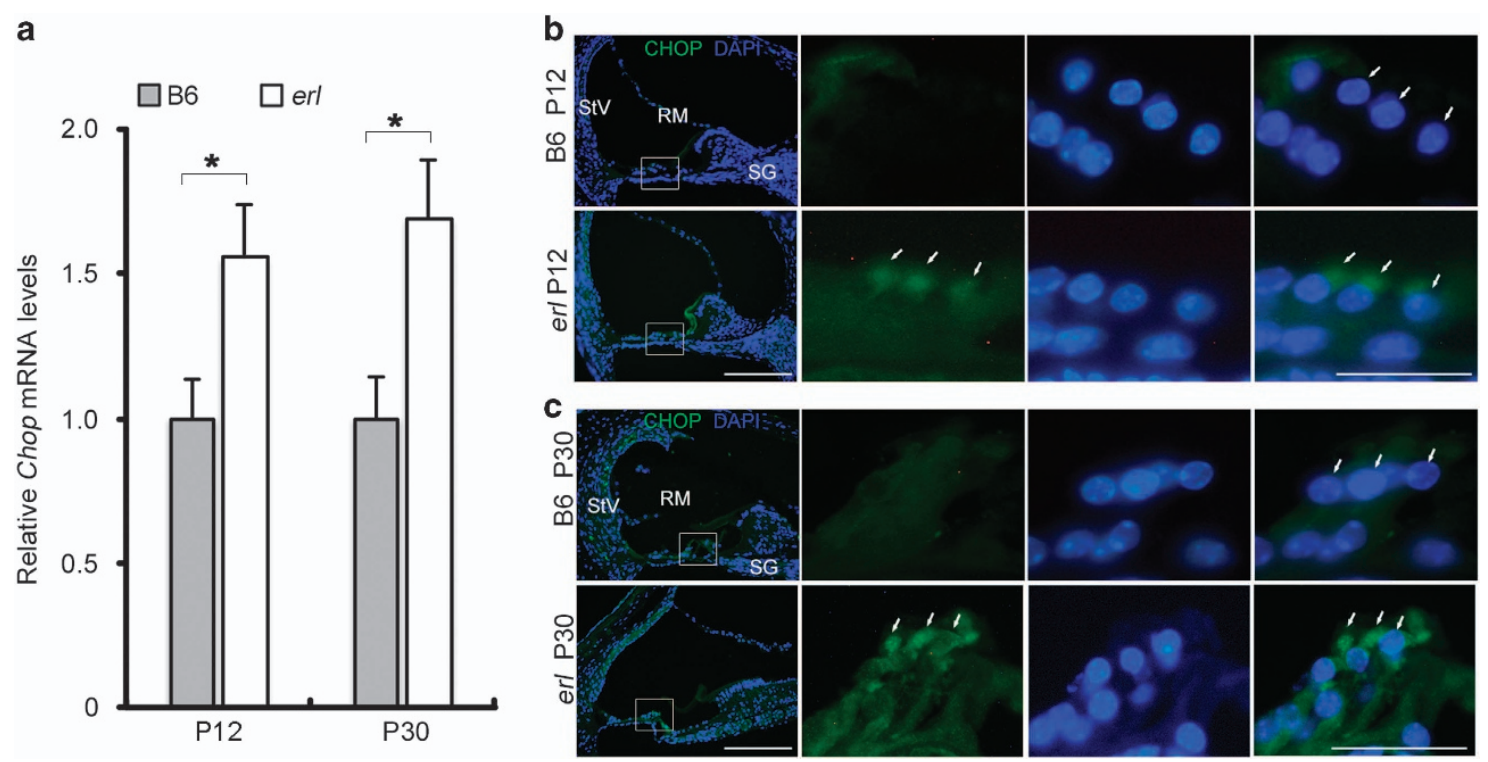

Figure 4 CHOP expression in the B6 and erl mouse cochleae. (a) The Chop mRNA levels in the cochleae of the B6 and erl mice at P12 and P30. The Chop mRNA level was significantly higher at P12 and P30 in the erl cochleae than in the B6 cochleae. The error bars represent S.E.M. $\left({ }^{*} P<0.05, n=3\right.$ mice, $t$-test). (b,c) CHOP maintained greater intensities in in stria vascularis (StV), spiral ganglion (SG), especially in the perinuclear region between nucleus and hair bundles of the OHCs in the erl mice at P12 and P30 ( $n=3$ mice per group). Scale bars, $50 \mu \mathrm{m}$ (left); $20 \mu \mathrm{m}$ (right) 
a
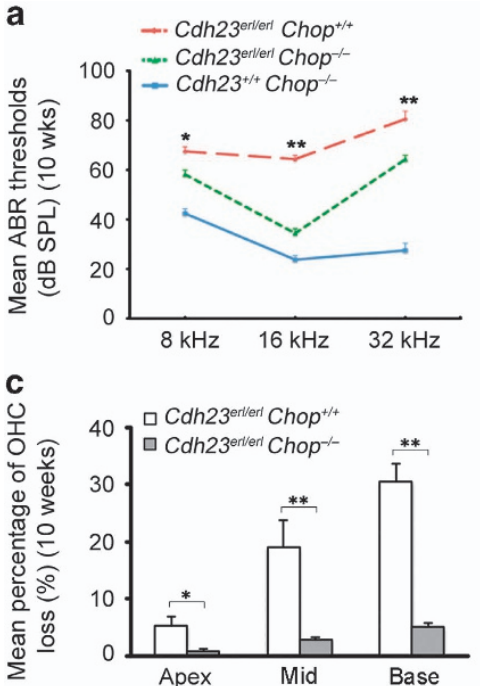

b

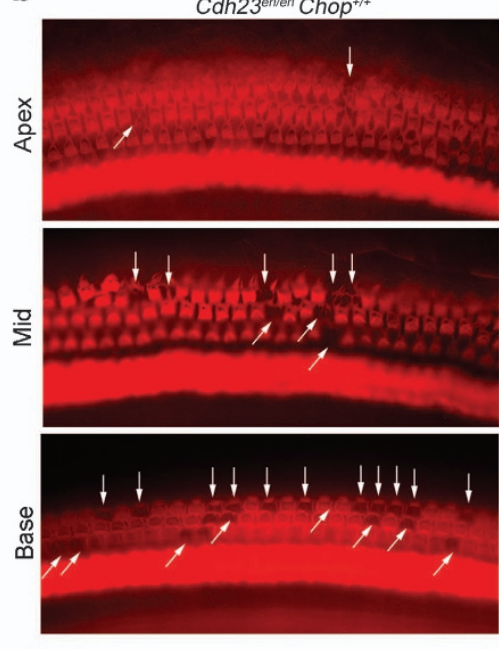

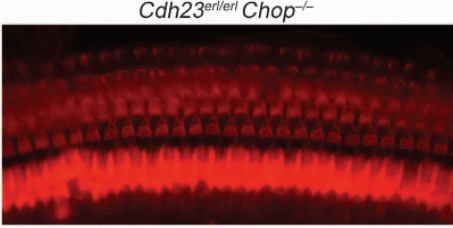

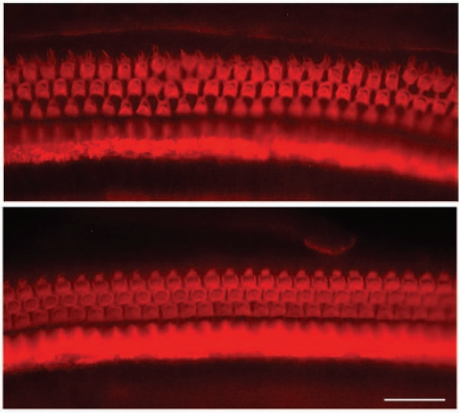

Figure 5 The hearing and $\mathrm{OHC}$ preservation in the $\mathrm{Cdh}_{2} 3^{\text {erl/erl }} \mathrm{Chop}^{-/-}$mice. (a) The ABR thresholds in the double-mutant Cdh23 ${ }^{\text {erl/erl }} \mathrm{Chop}{ }^{-/-}$mice, Chop ${ }^{-/-}$mice $\left(\mathrm{Cdh}_{2} 3^{+/+} \mathrm{Chop}^{-/-}\right)$and erl mice $\left(\mathrm{Cdh}_{2} 3^{\text {erl/erl }} \mathrm{Chop}^{+/+}\right.$) at 8,16 and $32 \mathrm{k} \mathrm{Hz}$ stimuli at 10 weeks. The Chop ${ }^{-/-}$mice showed normal hearing levels. The erl mice exhibited hearing impairment during all stimuli. The $\mathrm{Cdh}_{2} 3^{\text {erlerl }} \mathrm{Chop}^{-l-}$ double-mutant mice showed lower ABR thresholds than the erl mice during all stimuli. The error bars represent S.E.M. ( ${ }^{* *} P<0.01,{ }^{*} P<0.05, n=8$ mice, $t$-test). (b) The whole-mount preparations from the basal, middle and apical turns of the cochleae were stained for F-actin in the $\mathrm{Cdh}_{23}{ }^{\text {erl/erl }} \mathrm{Chop}^{-1-}$ mice and erl mice at 10 weeks. The erl mice showed some OHC losses in the apical turn and evident OHC loss in the middle and basal turns. No OHC loss was observed in the whole lengths of the $\mathrm{Cdh}_{2} 3^{\text {erllerl }} \mathrm{Chop}^{-1-}$ double-mutant cochleae. Scale bar, $20 \mu \mathrm{m}$. (c) The mean percentages of OHC loss in the apical, middle

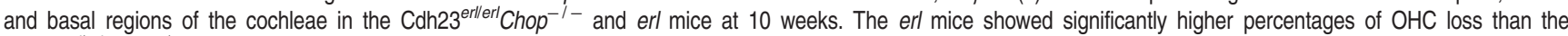
Cdh23 ${ }^{\text {erl/erl }}$ Chop $^{-1-}$ mice. The error bars represent S.E.M. $\left({ }^{\star \star} P<0.01,{ }^{\star} P<0.05, n=5\right.$ mice, $t$-test)
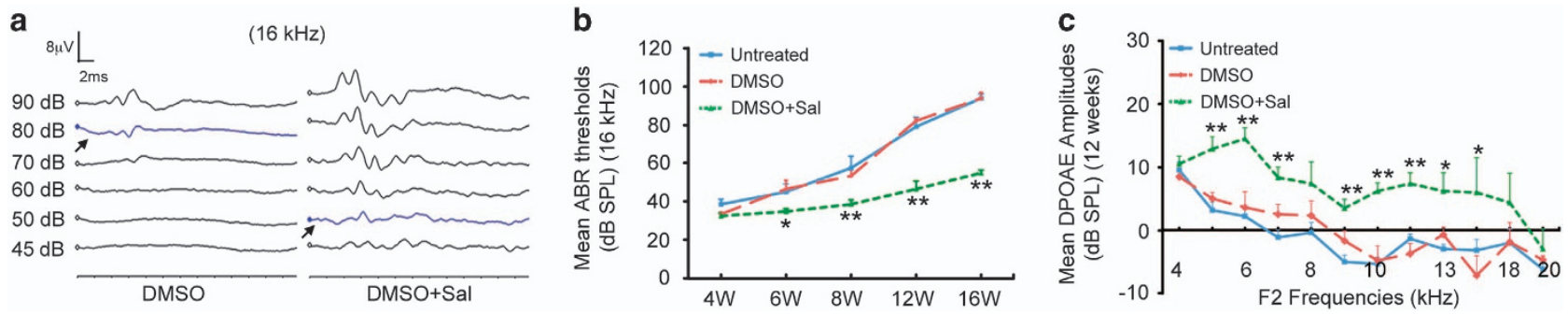

Figure 6 Sal improved hearing in the er/mice. (a) At 12 weeks, the vehicle-treated mice showed much higher ABR thresholds than the Sal-treated mice at 16-kHz stimuli. The colored lines and arrows represent threshold waveforms. (b) The 16-kHz-stimulated-ABR thresholds in Sal-treated mice were significantly lower than those in the DMSO and untreated mice from 4 (W) to 16 weeks. No significant difference was found between the untreated and DMSO groups. (c) The DPOAE amplitudes in the Sal-treated mice were much higher than in the untreated and DMSO-treated mice at 12 weeks. No significant difference was found between the untreated and DMSO groups. The error bars represent S.E.M. ${ }^{\star \star} P<0.01,{ }^{*} P<0.05, n=5$ per group, one-way ANOVA)

vehicle and control groups at 12 weeks. OHC impairment was obvious in the vehicle and control groups, while $\mathrm{OHC}$ loss was very minimal in the test group (Figure 7a). In the vehicle and control groups, several substantial contiguous spots of $\mathrm{OHC}$ loss were observed in the basal and middle turns, and some $\mathrm{OHC}$ loss was seen in the apex turns. In contrast, the mice in the test group showed only small amounts of $\mathrm{OHC}$ loss in the basal turn and rare $\mathrm{OHC}$ loss in the middle turn. The mean percentage of $\mathrm{OHC}$ loss in the test group was significantly lower than that in the vehicle and control groups (Figure 7b). No significant difference was found between the vehicle and control groups.

A scanning electron microscope was used to analyze $\mathrm{OHC}$ morphology and subcellular structures at 12 weeks (Figure 7c). The images showed that untreated erl mice exhibited almost total $\mathrm{OHC}$ loss and no detectable subcellular structure of hair bundles in the basal turn. In contrast, the Sal-treated mice showed small amounts of $\mathrm{OHC}$ loss and approximate normal arrangements of hair bundles.

Sal suppressed ER stress-induced apoptosis in erl mice. ER stress and apoptosis-related genes and proteins were downregulated after the Sal treatments. The mRNA expression levels of BiP, Chop, caspase-3 and caspase-12 genes were tested at P30 and 12 weeks. The results showed that Bip and Chop decreased in the Sal group versus the vehicle group at P30, and caspase-3 was downregulated at 12 weeks (Figures $8 a$ and b). However, no significant difference was found in the caspase-12 gene expression (Supplementary Figure 4). $\mathrm{BiP}$ and cleaved caspase-3 protein extracted from the 
a
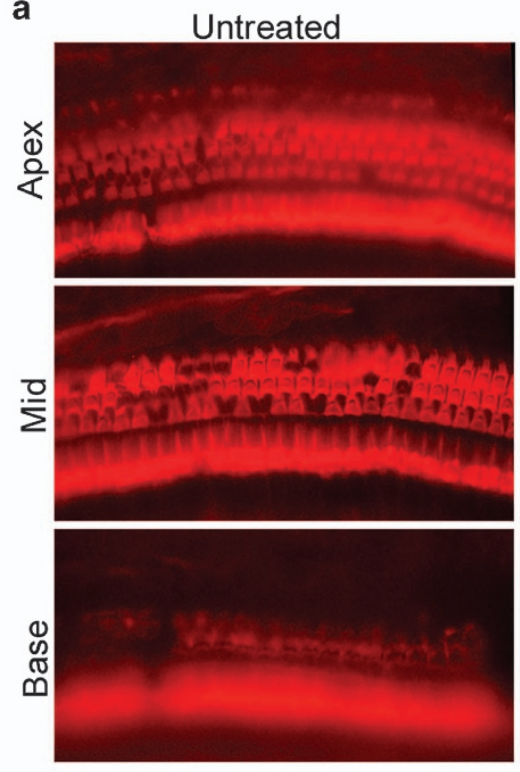

b

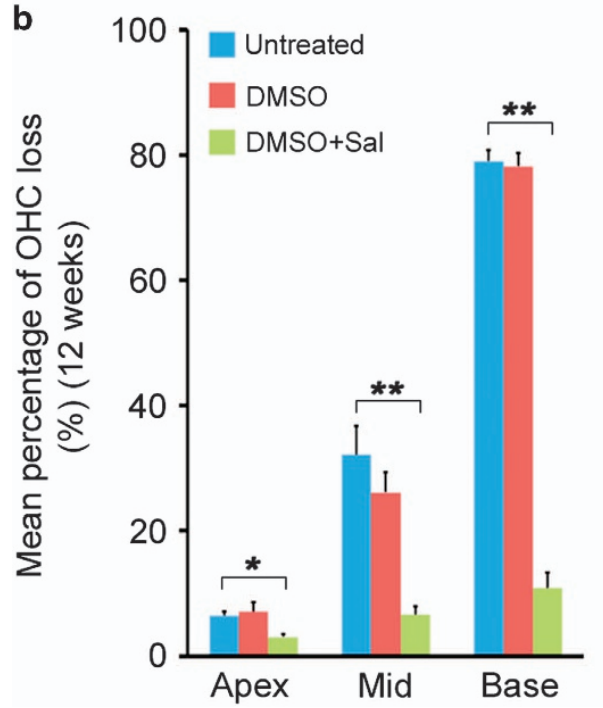

DMSO
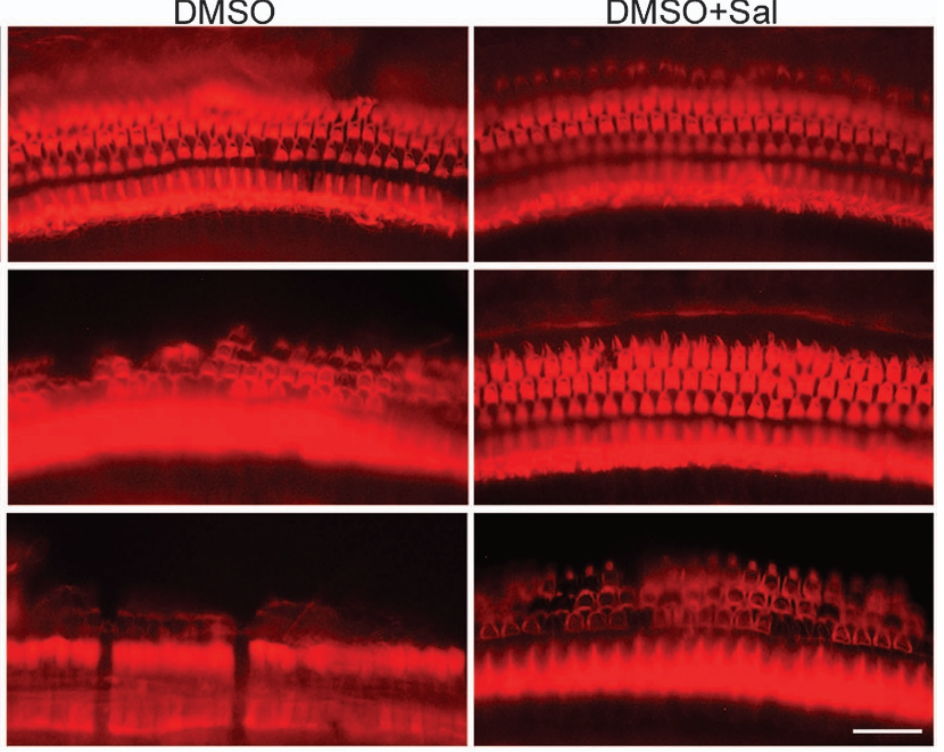

C
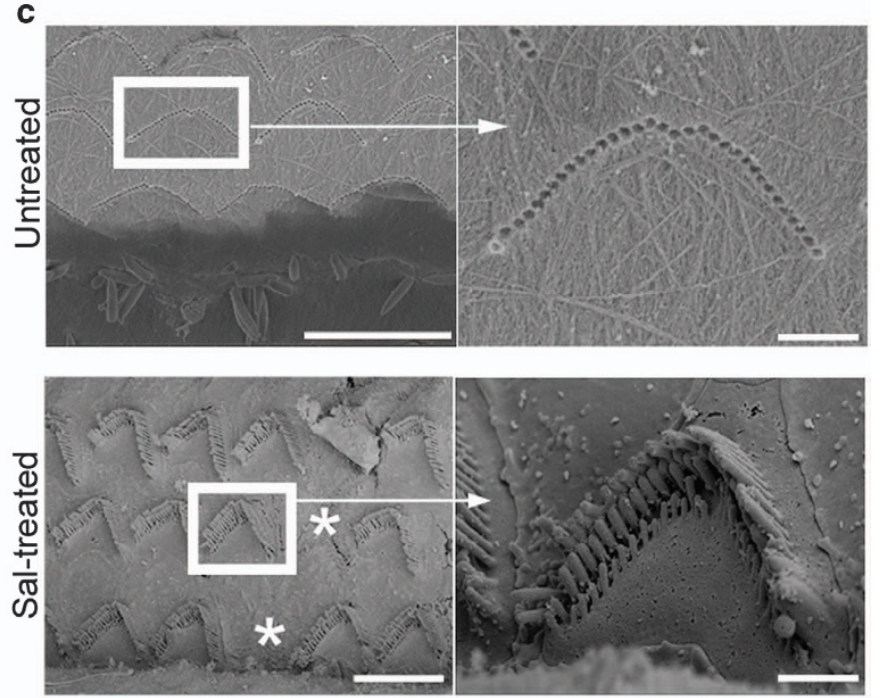

Figure 7 Sal prevented OHC loss in the erl mice. (a) The whole-mount preparations from the basal, middle and apical turns of the cochleae in the untreated, DMSO-treated and Sal-treated mice at 12 weeks. In the vehicle and control groups, OHC loss was observed in the basal and middle turns, and such losses were more pronounced in the basal turn. In the apical turn, the vehicle and control groups showed disorganized OHC patterns but almost no cell loss. The test group showed small amounts of OHC loss in the basal and middle turns and a normal arrangement in the apical turn. Scale bar, $20 \mu \mathrm{m}$. (b) The mean percentages of OHC loss in the apical, middle and basal regions of the cochleae in the Sal-treated mice were significantly lower than in the untreated and DMSO-treated mice at 12 weeks. No significant differences were observed between the DMSO and untreated groups. The error bars represent S.E.M. ( ${ }^{* *} P<0.01,{ }^{*} P<0.05, n=4$ per group, one-way ANOVA). (c) The OHC morphology and subcellular structures by scanning electron microscope from the basal turns of the cochleae of untreated and Sal-treated erl mice at 12 weeks. The untreated mice showed almost total OHC loss and mild inner-hair cell loss in the basal turn. The Sal-treated mice showed little $\mathrm{OHC}$ loss and an almost normal arrangement of hair bundles. Stars mark the $\mathrm{OHC}$ losses. Scale bars, $10 \mu \mathrm{m}$ (left); $1 \mu \mathrm{m}$ (right)

erl mouse cochleae in the vehicle and test groups were measured by Western blot at P30. The results showed that $\mathrm{BiP}$ and cleaved caspase- 3 were much less abundant in the Sal-treated cochleae than in the vehicle-treated cochleae (Figures 8c). Furthermore, CHOP was immunolabeled in the vehicle and test groups at P30. The results showed that the CHOP signals in the OHCs, SG and StV in DMSO-treated cochleae were distinctly weakened by Sal treatment, and the most significant difference in $\mathrm{CHOP}$ expression was seen in the perinuclear regions of the $\mathrm{OHCs}$ (Figures 8d).

\section{Discussion}

As a novel mutation of the Cdh23 gene, the erl mutant mice exhibited the postnatal onset of hearing loss starting at P27, which progressed to total deafness at $\sim \mathrm{P} 100$. This is considered to be an animal model for human DFNB12. ${ }^{10}$ 


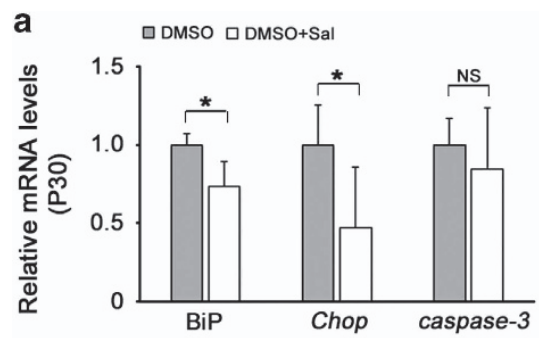

C
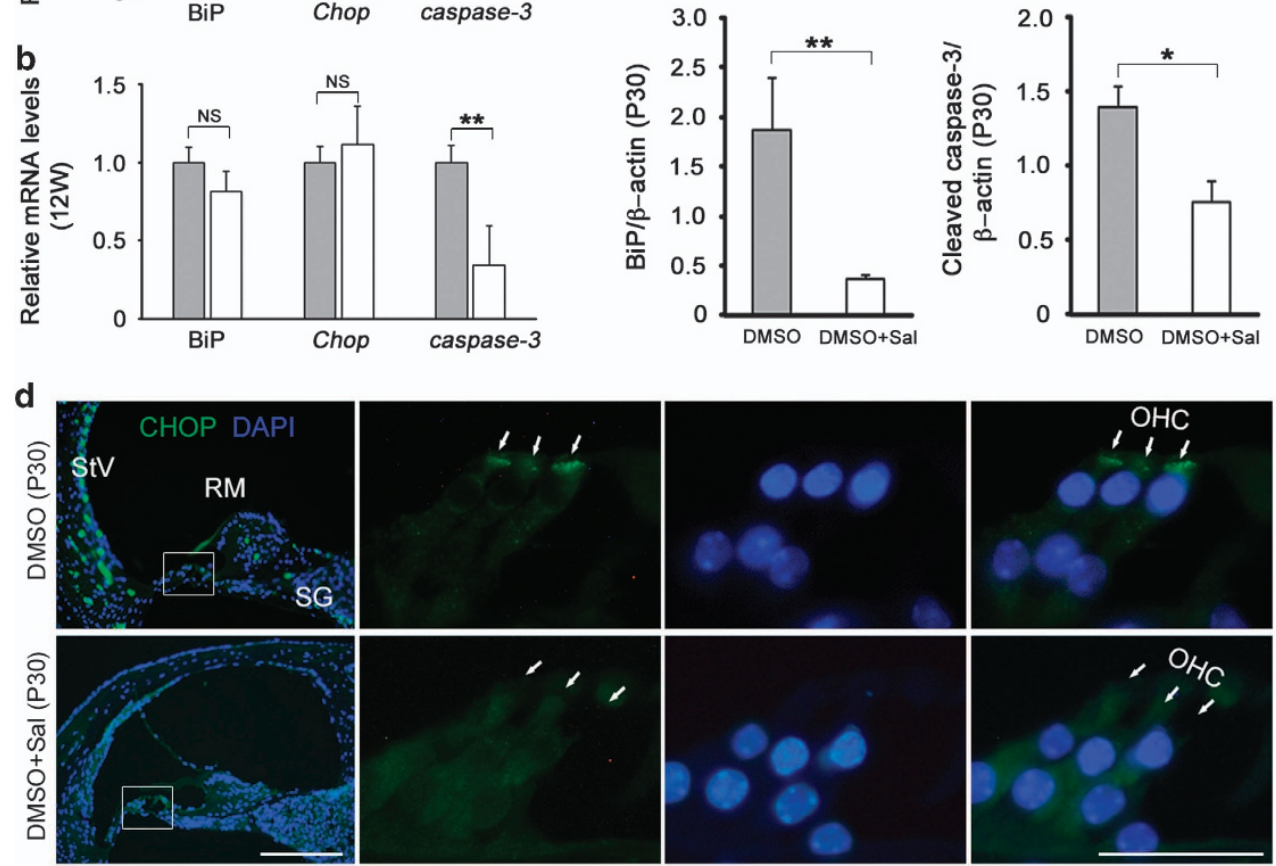

Figure 8 Sal downregulated ER stress and apoptosis-related genes and proteins. (a) BiP and Chop mRNA were downregulated in the Sal-treated mice at P30. However, no significant difference was found in the Caspase-3 mRNA levels $\left({ }^{\star \star} P<0.01,{ }^{*} P<0.05\right.$, NS, not significant, $n=3$, $t$-test). (b) At 12 weeks, the Caspase-3 mRNA levels were remarkably downregulated in the Sal-treated mice compared with DMSO-treated mice; however, no significant differences were found in the BiP and Chop mRNA levels $\left({ }^{\star \star} P<0.01,{ }^{\star} P<0.05\right.$, NS, not significant, $n=3, t$-test). (c) The BiP and cleaved caspase-3 protein levels in the cochleae from the Sal-treated mice were much lower than those from the DMSO-treated mice at P30. Significant differences were found between the DMSO and Sal-treated mice in their quantities of BiP and cleaved caspase-3. The error bars represent S.E.M. ( ${ }^{\star \star} P<0.01,{ }^{*} P<0.05$, NS, not significant, $n=3$, t-test). (d) CHOP signals were more strongly detected in the OHCs, SG and StV of the DMSO-treated mice, showing high concentration in the perinuclear region in between nucleus and hair bundles of OHCs but attenuated by Sal ( $n=3$ mice per group). Scale bars, $50 \mu \mathrm{m}$ (left); $20 \mu \mathrm{m}$ (right)

Given their time window from initial hearing-loss initiation to total deafness, these mutant mice are ideal tools for testing new otoprotective drugs. We previously revealed that erl mice treated with erythropoietin and Z-VAD-FMK could be significantly protected against $\mathrm{OHC}$ death and rescued from hearing loss through the blocking of the apoptosis pathway in erl mice. ${ }^{10,16}$ In the current study, the upstream apoptosis response in the erl cochleae was discovered to be relevant to ER stress and the UPR.

Under the quality-control surveillance of the $E R$, only correctly folded proteins can be transferred by the Golgi complex and sent to their final destinations, while unfolded or misfolded proteins are retained in the ER and ultimately degraded by the ubiquitin-dependent proteolytic pathway or autophagy. ${ }^{17,18}$ The accumulation and aggregation of unfolded or misfolded proteins in the ER lumen increase ER loading and disrupt ER homeostasis, ultimately leading to ER stress. ${ }^{19,20}$ Under mild-to-moderate stimulation, ER stress is an adaptive and restorative response that leads to cell adaptation. In contrast, if the stress is beyond the ER's adaptive capacity, the protective signaling will switch to pro-apoptotic responses. ER stress has been linked to the pathogenesis of neurodegenerative diseases, such as Alzheimer's disease and Parkinson's disease, as well as to the pathogenesis of cell death, such as renal tubule lesions in diabetes. ${ }^{21-23}$ In zebrafish mutants, the defective $\mathrm{CDH} 23$ proteins in hair cells failed to be transferred and contributed to the formation of Usher protein complexes, therefore leading to ER stress. ${ }^{15}$ Taken together, these results offered us new insight into the pathological mechanisms of and potential therapies for sensorineural deafness. Using an animal model for mammals, we questioned whether similar protein-folding defects and the activation of ER stress happened in mice with the Cdh23 mutation.

We provided evidence that part of the ERL-CDH23 protein exhibited abnormal localization in the $\mathrm{OHC}$ (from the stereocilia to the nucleus, Figure 1a), failing to reach the top of hair bundles and thus leading to reduced migration to the tip links. 
Moreover, the ERL-CDH23 protein in the subapical region of the $\mathrm{OHC}$ was co-localized with ER chaperone BiP (Figures $1 \mathrm{~b}$ and $\mathrm{c}$ ). The BiP protein was found to be highly expressed in OHCs, SG and StV in the erl cochleae at P6 and P12, and the BiP mRNA was upregulated at P12 but downregulated at P30 (Figure 2). Considering the UPR pathway, these results suggest that $\mathrm{BiP}$ was dissociated with the ER transmembrane receptor and then combined with defective $\mathrm{CDH} 23$ at the early stage of this response. Downstream of this pathway, elF2a phosphorylation was detected in the erl cochleae (Figure 3), and the Chop mRNA and protein were upregulated at P12 and P30 (Figure 4). These results indicate that the PERK arm of the UPR was activated. CHOP was a key mediator when the ER stress-induced UPR signaling progressed to apoptosis. ${ }^{24,25}$ The results of the auditory test, surface preparation and $\mathrm{OHC}$ counting in our double-mutant Cdh $23^{\text {erl/erl }}$ Chop $^{-1-}$ mice further confirm that the deletion of the Chop gene could partly protect hearing and preserve the $\mathrm{OHC}$ in mice with the Cdh23 $3^{\text {erl/erl }}$ mutation (Figure 5). Taking these data together with the previous study on the induction of apoptosis-related genes in the erl mouse cochleae, ${ }^{10}$ we suggest that apoptosis is an event downstream of the induction of the UPR, with the effector PERK signaling pathway being a contributor. Thus, we selected the PERK arm of the UPR as a therapeutic target.

It is interesting to note that CHOP does not present nuclear localization in OHCs, as expected for a transcription factor (Figures 4 and 8). However, CHOP does not have a nuclear localization signal. Its interaction with other stress-induced transcription factors mediates its nuclear localization. ${ }^{26}$ It is therefore possible that in $\mathrm{OHCs}, \mathrm{CHOP}$ is excluded from the nucleus due to the absence of interacting transcription factor partners. It was also reported that cells with cytoplasmic and nuclear localized CHOP gave distinct gene expression profiles. It was shown that that cytoplasmic CHOP inhibited the migration, while nuclear CHOP caused a G1 cell cycle arrest. $^{27}$ In this erl model, particularly in OHCs, CHOP is localized in the perinuclear regions in between the nuclei and hair bundles of the OHCs. An OHC develops a polarized bundle of stereocilia that is important for mechanotransduction. ${ }^{28}$ Many hair bundle proteins migrate toward the hair bundle; thus, we speculate that the cytoplasmic CHOP may regulate the expression of protein migration-related genes. Further study is warranted on CHOP's role(s) aside from inducing apoptosis on $\mathrm{OHC}$ degeneration and functionality.

Sal is a small molecular compound $(480 \mathrm{Da})$ that prevents cell death from ER stress-induced apoptosis by selectively inhibiting the dephosphorylation of elF2a. ${ }^{29}$ Studies show that Sal resists ER stress-induced cell death, improves cell survival and delays disease processes. ${ }^{30-34}$ Our hearing tests confirmed our hypothesis that Sal could protect hearing by inhibiting ER stress-induced hair cell apoptosis in the erl mice. In a previous work, we reported that progressive hearing loss started at P27 in erl mice. ${ }^{10}$ In this study, as early as 4 weeks postnatal, the $32-\mathrm{kHz}$-stimulus-evoked ABR thresholds in the test group were $10 \mathrm{~dB}$ better than in the control and vehicle groups (Supplementary Figure 1b). At all subsequent time points, the Sal-treated mice showed better ABR thresholds under all stimuli. Referring to the correspondence between high and low frequencies and to the basal-apical gradient of the basilar membrane, ${ }^{35,36}$ the auditory tests indicate that the $\mathrm{OHC}$ death specifically started in the basal turns and then spread through the entire cochleae, which could be remedied by Sal treatment. Our previous studies targeting anti-apoptosis treatments also showed otoprotective effects, ${ }^{10,16}$ but Sal showed an extended duration (up to 16 weeks). In our histological examination, we observed substantial contiguous and isolated $\mathrm{OHC}$ losses in the vehicle and control groups; in contrast, the Sal-treated mice showed only small amounts of $\mathrm{OHC}$ loss (Figure 7). This result provides a good correlation between our anatomical observations and functional tests.

After the Sal treatment, the upregulated Bip and Chop mRNA were decreased at P30, and the caspase-3 was decreased at 12 weeks (Figure 8a), indicating that Bip and Chop were affected by Sal treatment at an early age and that the caspase-3 mRNA was influenced later. However, the cleaved caspase-3 proteins (detected by western blot) were found to be decreased by Sal at P30. Our cleaved caspase-3 antibody (Asp175) was able to recognize the large fragment (17 kDa) of activated caspase-3 resulting from the cleavage adjacent to Asp175, but it was incapable of detecting the fulllength caspase-3 protein. These results suggest that the caspase- 3 cleavage was blocked at P30 by Sal treatment. The caspase-12mRNA remained unchanged at $\mathrm{P} 30$ and 12 weeks (Supplementary Figure 4), indicating that caspase-12 might not be involved in the feedback of the Sal treatment. The BiP proteins (detected by Western blot) and CHOP proteins (detected by immunostaining) were also downregulated after Sal treatment (Figure 8). These results, together with the previous data, ${ }^{10}$ suggest that the defective $\mathrm{CDH} 23$ accumulated in the ER and then increased the ER loading and destroyed ER homeostasis, leading to the dissociation of the BiP from PERK. The downstream upregulated CHOP led to caspase activation and apoptosis. If the adaptive UPR reduces the protein load in the $E R$, then the restoration of protein synthesis will promote cell survival. Otherwise, if protein synthesis overrides the restoration of proteostasis, cell death will be triggered. ${ }^{37}$ Sal inhibits the dephosphorylation of elF2a, which inhibits protein synthesis when it is phosphorylated by PERK. This increased phosphorylation of elF2a limits protein synthesis (including that of $\mathrm{CDH} 23$ and $\mathrm{CHOP}$ ), relieves ER loading, and promotes cell survival. Potential mechanisms of the pro-apoptotic function of uncontrolled protein synthesis during ER stress have recently been described. $^{37,38}$

As an animal model of DFNB12, the erl mice with Sal treatment began at an early age (starting from P7) and showed significant hearing protection for a long duration (up to 16 weeks). By considering the signaling pathway of ER stress-induced apoptosis, we suggest that therapies targeting this specific signaling pathway could prevent hair cell loss at an early stage and achieve more effective and sustained results. USH1D patients who carry different mutations of the same gene (Cdh23) as DFNB12 exhibit congenital deafness and postnatal-onset blindness. Thus, we assume that early treatment with Sal might prevent ophthalmic dysfunction in Usher syndrome, thus highlighting Sal's application as a 
therapeutic agent in the treatment of animal models for Usher syndrome.

\section{Conclusion}

In summary, this study is the first to consider ER stressinduced hair cell apoptosis as having a key role in the hearing loss and hair cell death of mice with the Cdh23 mutation. Protein synthesis and related protein-folding processes are early molecular events in ER stress and apoptosis. Thus, protein-folding errors triggered by genetic mutations should be considered the earliest therapeutic target. Many Food and Drug Admission (FDA)-approved anti-ER stress drugs are presently available on the market and thus can be repurposed for otoprotection.

\section{Materials and Methods}

Experimental design. This study aimed at assessing ER stress-induced hair cell apoptosis in the mechanism of hearing loss and hair cell death in Cdh23erl/erl mutant mice. The measurements of ER stress indicators were performed between Cdh23 $3^{\text {erlerl }}$ mutant mice, control B6 mice, as well as the Chop gene knockout (C57BL/6 background) mice. The ER stress inhibitor Salubrinal (Sal) was systematic given in $\mathrm{Cdh} 23^{\text {erl/erl }}$ mutant mice by intraperitoneal injection. The hearing, OHC reservation and ER stress indicators were tested between Sal-treated, vehicle-treated and untreated Cdh23 $3^{\text {erlerl }}$ mice.

Mice. All of the procedures involving mice were approved by the Animal Research Committee of Case Western Reserve University School of Medicine (protocol R01DC009246). All of the mice were experimented upon in the same environment and bright-dark circle. The erl mice were first housed in the Jackson Laboratory (Bar Harbor, ME, USA) before this mutant strain was relocated to Case Western Reserve University. Mice with the Chop gene knockout (C57BL/6 background) were introduced from the Jackson Laboratory (stock number 005530). The homozygous erl mice (Cdh23 $3^{\text {erlerl }}$ ) were crossed with the homozygous Chop gene knockout mutants $\left(\mathrm{Chop}^{-1-}\right)$, generating F1 with the genotype of $\mathrm{Cdh}_{23^{+/ e r l}} \mathrm{Chop}^{+-}$. Then, the F1 $\left(\mathrm{Cdh}_{2} 3^{+/ \text {rrl }} \mathrm{Chop}^{+/}\right)$was crossed with $\mathrm{F} 1\left(\mathrm{Cdh}_{2} 3^{+/ 2 r l} \mathrm{Chop}^{+/}\right)$to generate

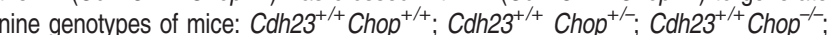
$\mathrm{Cdh}_{23^{+/ e r l}} \mathrm{Chop}^{+/+}$; Cdh23 ${ }^{+/ e r l} \mathrm{Chop}^{+/}$; Cdh23 ${ }^{+/ e r l} \mathrm{Chop}^{-/}$; Cdh23 ${ }^{\text {erl/erl }} \mathrm{Chop}^{+/+}$; Cdh23 $3^{\text {erlerl }} \mathrm{Chop}^{+-}$; and $\mathrm{Cdh}_{2} 3^{\text {erl/erl }} \mathrm{Chop}^{-/-}$. Then, we selected the homozygous Cdh2 $3^{\text {erlerl }} \mathrm{Chop}^{--}$, which were intercrossed and maintained as an inbred mouse line. Because the Chop gene knockout and the erl mutation mice are both come from the C57BL/6 background, we chose Cdh23 $3^{\text {erl/erl }} \mathrm{Chop}^{-1}$, Cdh23 $3^{\text {erlerl }}$ $\mathrm{Chop}^{+/+}$(erl mice) and Cdh $23^{+/+} \mathrm{Chop}^{-/}\left(\mathrm{Chop}^{-/}\right.$mice $)$for our experiments.

The genotyping for erl mice was described previously. ${ }^{10}$ The genotype for $\mathrm{Chop}^{-1-}$ was determined by semi-quantitative PCR through the use of the following primers: olMR3884-5'-ATGCCCTTACCTATCGTG-3' (common); olMR3885 - 5'-AACGCCAG GGTTTTC CCAGTCA-3' (mutant reverse); and olMR3886 - 5'-GCAGGGTCA AGAGTAGTG-3' (wild-type reverse). The thermal cycle reaction was performed as follows: $94{ }^{\circ} \mathrm{C}$ for $3 \mathrm{~min}$, followed by 35 cycles at $94^{\circ} \mathrm{C}$ for $30 \mathrm{~s}, 61^{\circ} \mathrm{C}$ for $1 \mathrm{~min}$, $72{ }^{\circ} \mathrm{C}$ for $1 \mathrm{~min}$ and $72{ }^{\circ} \mathrm{C}$ for $2 \mathrm{~min}$. The wild-type showed one band (544 bp), whereas the heterozygotes showed two bands ( 320 and $544 \mathrm{bp}$ ) and the mutants showed one band (320 bp). The genotype for $\mathrm{Cdh}^{2} 3^{\text {erlerl }} \mathrm{Chop}^{--}$was determined by Cdh2 $23^{\text {erl/erl }}$ genotyping and $\mathrm{Chop}^{-/-}$genotyping.

Sal treatment. The erl mice received different treatments by intraperitoneal injection. In total, $70 \mathrm{erl}$ mice were divided into three groups with either gender: a test group (treated with Sal, $0.5 \mathrm{mg} \mathrm{kg}^{-1}$, R\&D ng Cat\# 2347), a vehicle group (treated with an equal volume of dimethylsulfoxide, DMSO), and a control group (untreated). All of the treatments started from postnatal $(P)$ day 7 , with subsequent injections occurring every other day for the first 12 weeks, every 3 days for 2 additional weeks, and then once every week for the duration of the experiments. The Sal dosage was selected from two sets of preliminary experiments, which showed it to be safe and hearing protective. The starting age of treatment was selected to prevent apoptotic gene upregulation in erl mice detected in our previous work. $^{10}$
PCR. The cochleae were quickly isolated, and then TRIzol (Invitrogen, Eugene, OR, USA) was used for total RNA extraction. The Super Script III First-Strand Synthesis System (Invitrogen) was used to synthesize cDNA. Quantitative PCR was performed with the reagent of SYBR Green FAST Mastermix (QIAGEN, Germantown, MD, USA) on an $\mathrm{ABI} 7300$ Sequence Detection System (Foster City, CA, USA). Primer sequences are listed in Table. S1. The cycle reaction was performed as follows: $95^{\circ} \mathrm{C}$ for $10 \mathrm{~min}, 40$ cycles of $95^{\circ} \mathrm{C}$ for $15 \mathrm{~s}$ and $60^{\circ} \mathrm{C}$ for $1 \mathrm{~min}$, and finally a dissociation curve of $95^{\circ} \mathrm{C}$ for $15 \mathrm{~s}$ and $60^{\circ} \mathrm{C}$ for $15 \mathrm{~s}$. The gene expression was calculated relative to the housekeeping gene GAPDH and then analyzed using the $2^{-\Delta \Delta C T}$ method. Semi-quantitative PCR was performed using the DNA Engine (Bio-Rad, Hercules, CA, USA) with the cycle reaction described above.

Western blotting. The cochleae were lysed using ice-cold RIPA buffer. Equal amounts of protein were subjected to SDS-PAGE and transferred onto the PVDF (Bio-Rad) membrane. Afterward, the PVDF membrane was blocked for $1 \mathrm{~h}$ in $5 \%$ ECL prime blocking agent and then incubated overnight at $4{ }^{\circ} \mathrm{C}$ with 1:1000 diluted primary antibodies: anti-BiP (Cell Signaling 3177, Danvers, MA, USA), anti-caspase-3 (Cell Signaling 9661) and anti- $\beta$-actin (Santa Cruz sc-130657). After washing with TBST, the membrane was incubated in secondary antibodies (1:5000, goat anti-rabbit IgG, Santa Cruz sc-2054). Protein bands were visualized using the chemiluminescence-emanating ChemiDoc MPImaging System (Bio-Rad).

Immunofluorescence staining. The inner ears were fixed in $4 \%$ paraformaldehyde (PFA) overnight and then decalcified in 10\% ethylenediaminetetraacetic acid (EDTA). After being dehydrated in sucrose and embedded in tissue OCT freeze medium at $-20^{\circ} \mathrm{C}, 6 \mu \mathrm{m}$ continuous sections were cut. These sections were permeabilized in $0.5 \%$ Triton $\mathrm{X}-100$ for $30 \mathrm{~min}$, blocked in $3 \%$ BSA for $2 \mathrm{~h}$ at room temperature, and then incubated overnight at $4{ }^{\circ} \mathrm{C}$ with 1:200 diluted primary antibodies: anti-CDH23 (Santa Cruz sc-26338), anti-BiP (Cell Signaling 3177), anti-CHOP (Santa Cruz sc-575), anti-elF2a (Cell Signaling 9722) and antiphospho-elF2a (Cell Signaling 3597). Secondary antibodies with 1:400 dilution (donkey anti-rabbit lgG, Invitrogen A31573; rabbit anti-goat IgG, Invitrogen A11078) were added for $1 \mathrm{~h}$; the sections were then counter-stained with DAPI. The negative controls (with no primary antibodies added) showed no staining.

ABR and DPOAE testing. A computer-aided evoked potential system (Intelligent Hearing Systems, the Smart-EP software 3.30, Miami, FL, USA) was used as previously published. ${ }^{39}$ Briefly, the mice were anesthetized, and their body temperature was maintained at $37^{\circ} \mathrm{C}$. Sub-dermal needle electrodes were used. The recording electrode was inserted at the vertex of the skull; the ground electrode was inserted in the apex of the nose; and the reference electrodes were fixed near each ear. Click and 8, 16 and $32 \mathrm{kHz}$ tone bursts were channeled through an inserted earphone. The ABR threshold was identified as the lowest stimulus level at which clear and repeatable waveforms were recognized (Figure 2a). The DPOAE measurement was conducted for pure tones at frequencies ranging from 4.4 to $20.3 \mathrm{kHz}$ by using the Intelligent Hearing System (Smart EP 3.30 Software). Frequencies were acquired with the F2:F1 ratio of 1.22 and with primary stimulus of $65 / 55 \mathrm{~dB} S P L$.

Surface preparation and hair cell counting. As we previously described, ${ }^{40}$ the temporal bones were fixed in $4 \%$ PFA, and the basilar membrane was then carefully dissected and cut into three separate fragments: apical, middle and basal turn. The fragments were permeabilized in $2 \%$ Triton X-100, stained for F-actin with phalloidin (Invitrogen), and observed with a fluorescence microscope (Leica DM4500 B). Hair cells were counted as being present if cell bodies and the V-shaped hair bundles were intact.

Confocal 3D imaging. To determine CDH23 localization in OHCs, wholemount immunostaining of inner ear basilar membranes from 4-day-old mice was conducted using primary antibody anti-CDH23 (Santa Cruz, sc-26338), secondary rabbit anti-goat IgG, Invitrogen A11078, Alexa 488 (1:1000 dilution), then counterstained with DAPI. Confocal images were captured using a Leica (Germany) SP8 confocal microscope with a $\times 63 / 1.4 \mathrm{NA}$ oil objective and a $488 \mathrm{~nm}$ laser-line. Imaging stacks acquired with voxel-size $512 \times 512 \times 0.045 \mu \mathrm{m}^{3}$ and $1024 \times 1024 \times 0.027 \mu \mathrm{m}^{3}$, respectively depending on the sizes of $\mathrm{OHCs}$, All deconvolutions were processed using Leica Application Suite X (LAS X, LASX) software.

Scanning electron microscope. The mice were fixed with $2.5 \%$ glutaraldehyde, and then the whole cochleae were dissected. The bony capsule, spiral ligament, and Reissner's membrane were carefully removed to expose the 
whole organ of Corti. Afterwards, the specimens were fixed in $1 \%$ osmium tetroxide (OsO4) for $1 \mathrm{~h}$ three times and in $1 \%$ thiocarbohydrazide (TCH) for $1 \mathrm{~h}$ twice (the OTOTO technique). The specimens were dehydrated in a gradient ethanol series, critical-point dried using $\mathrm{CO}_{2}$, and finally coated in palladium. Then, the samples were viewed under a high-resolution scanning electron microscope (FEl Helios NanoLab 650, Germany).

Statistical analysis. The data are presented as mean \pm S.E.M. The analysis was performed using the SPSS 18.0 software. The data were statistically analyzed using one-way ANOVA and Student's $t$-tests. $P$-values $<0.05$ were considered significant.

\section{Conflict of Interest}

The authors declare no conflict of interest.

Acknowledgements. This project was supported by the China Scholarship Council (201306280095), the National Institutes of Health (R01DC015111, R01 DK053307 and R01DK060596), the Foundation of Taishan Scholar (tshw20110515) and the National Natural Science Foundation of China $(81271085,81530030$, 81400467 and 81600809 ).

1. Siemens J, Lillo C, Dumont RA, Reynolds A, Williams DS, Gillespie PG et al. Cadherin 23 is a component of the tip link in hair-cell stereocilia. Nature 2004; 428: 950-955.

2. Kazmierczak P, Sakaguchi H, Tokita J, Wilson-Kubalek EM, Milligan RA, Muller U et al. Cadherin 23 and protocadherin 15 interact to form tip-link filaments in sensory hair cells. Nature 2007; 449: 87-91.

3. Peng AW, Salles FT, Pan B, Ricci AJ. Integrating the biophysical and molecular mechanisms of auditory hair cell mechanotransduction. Nat Commun 2011; 2: 523.

4. Miyagawa M, Nishio S-y, Usami S-i. Prevalence and clinical features of hearing loss patients with CDH23 mutations: a large cohort study. Plos One 2012; 7: e40366.

5. Bolz H, von Brederlow B, Ramirez A, Bryda EC, Kutsche K, Nothwang HG et al. Mutation of $\mathrm{CDH} 23$, encoding a new member of the cadherin gene family, causes Usher syndrome type 1D. Nat Genet 2001; 27: 108-112.

6. Bork JM, Peters LM, Riazuddin S, Bernstein SL, Ahmed ZM, Ness SL et al. Usher syndrome 1D and nonsyndromic autosomal recessive deafness DFNB12 are caused by allelic mutations of the novel cadherin-like gene $\mathrm{CDH} 23$. Am J Hum Genet 2001; 68: 26-37.

7. Miyasaka Y, Suzuki S, Ohshiba Y, Watanabe K, Sagara Y, Yasuda SP et al. Compound heterozygosity of the functionally null Cdh23 (v-ngt) and hypomorphic Cdh23 (ahl) alleles leads to early-onset progressive hearing loss in mice. Exp Anim 2012; 62: 333-346.

8. Schwander M, Xiong W, Tokita J, Lelli A, Elledge HM, Kazmierczak P et al. A mouse model for nonsyndromic deafness (DFNB12) links hearing loss to defects in tip links of mechanosensory hair cells. Proc Natl Acad Sci USA 2009; 106: 5252-5257.

9. Manji SS, Miller KA, Williams LH, Andreasen L, Siboe M, Rose E et al. An ENU-induced mutation of $\mathrm{Cdh} 23$ causes congenital hearing loss, but no vestibular dysfunction, in mice. Am J Pathol 2011; 179: 903-914.

10. Han F, Yu H, Tian C, Chen HE, Benedict-Alderfer C, Zheng Y et al. A new mouse mutant of the $\mathrm{Cdh} 23$ gene with early-onset hearing loss facilitates evaluation of otoprotection drugs. Pharmacogenomics J 2012; 12: 30-44.

11. Hetz C, Mollereau B. Disturbance of endoplasmic reticulum proteostasis in neurodegenerative diseases. Nat Rev Neurosci 2014; 15: 233-249.

12. Hetz $C$. The unfolded protein response: controlling cell fate decisions under ER stress and beyond. Nat Rev Mol Cell Biol 2012; 13: 89-102.

13. Gorman AM, Healy SJ, Jager R, Samali A. Stress management at the ER: regulators of ER stress-induced apoptosis. Pharmacol Therapeut 2012; 134: 306-316.

14. Ron $D$, Walter $P$. Signal integration in the endoplasmic reticulum unfolded protein response. Nat Rev Mol Cell Biol 2007; 8: 519-529.

15. Blanco-Sanchez B, Clement A, Fierro J Jr., Washbourne P, Westerfield M. Complexes of Usher proteins preassemble at the endoplasmic reticulum and are required for trafficking and ER homeostasis. Dis Models Mech 2014; 7: 547-559.

16. Han F, Yu H, Zheng T, Ma X, Zhao X, Li P et al. Otoprotective effects of erythropoietin on Cdh23erl/erl mice. Neuroscience 2013; 237: 1-6.

17. Anelli T, Sitia R. Protein quality control in the early secretory pathway. EMBO J 2008; 27: 315-327.

18. Sitia R, Braakman I. Quality control in the endoplasmic reticulum protein factory. Nature 2003; 426: 891-894.
19. Zhang K, Kaufman RJ. The unfolded protein response A stress signaling pathway critical for health and disease. Neurology 2006; 66: S102-S109.

20. Boyce M, Yuan J. Cellular response to endoplasmic reticulum stress: a matter of life or death. Cell Death Differ 2006; 13: 363-373.

21. Lindholm D, Wootz H, Korhonen L. ER stress and neurodegenerative diseases. Cell Death Differ 2006; 13: 385-392.

22. Cooper AA, Gitler AD, Cashikar A, Haynes CM, Hill KJ, Bhullar B et al. $\alpha$-Synuclein blocks ER-Golgi traffic and Rab1 rescues neuron loss in Parkinson's models. Science 2006; 313 : 324-328.

23. Doyle KM, Kennedy D, Gorman AM, Gupta S, Healy SJ, Samali A. Unfolded proteins and endoplasmic reticulum stress in neurodegenerative disorders. J Cell Mol Med 2011; 15: 2025-2039.

24. Tabas I, Ron D. Integrating the mechanisms of apoptosis induced by endoplasmic reticulum stress. Nat Cell Biol 2011; 13: 184-190.

25. Malhi H, Kaufman RJ. Endoplasmic reticulum stress in liver disease. J Hepatol 2011; 54: 795-809.

26. Chiribau CB, Gaccioli F, Huang CC, Yuan CL, Hatzoglou M. Molecular symbiosis of CHOP and C/EBP beta isoform LIP contributes to endoplasmic reticulum stress-induced apoptosis. Mol Cell Biol 2010; 30: 3722-3731.

27. Jauhiainen A, Thomsen C, Strombom L, Grundevik P, Andersson C, Danielsson A et al. Distinct cytoplasmic and nuclear functions of the stress induced protein DDIT3/CHOP/ GADD153. PLoS One 2012; 7: e33208.

28. Sienknecht UJ. Current concepts of hair cell differentiation and planar cell polarity in inner ear sensory organs. Cell Tissue Res 2015; 361: 25-32.

29. Boyce M, Bryant KF, Jousse C, Long K, Harding HP, Scheuner D et al. A selective inhibitor of elF2alpha dephosphorylation protects cells from ER stress. Science 2005; $\mathbf{3 0 7}$ 935-939.

30. D'Antonio M, Musner N, Scapin C, Ungaro D, Del Carro U, Ron D et al. Resetting translational homeostasis restores myelination in Charcot-Marie-Tooth disease type 1B mice. J Exp Med 2013; 210: 821-838.

31. Sokka AL, Putkonen N, Mudo G, Pryazhnikov E, Reijonen S, Khiroug L et al. Endoplasmic reticulum stress inhibition protects against excitotoxic neuronal injury in the rat brain. J Neurosci 2007; 27: 901-908.

32. Saxena S, Cabuy E, Caroni P. A role for motoneuron subtype-selective ER stress in disease manifestations of FALS mice. Nat Neurosci 2009; 12: 627-636.

33. Kim JS, Heo RW, Kim H, Yi CO, Shin HJ, Han JW et al. Salubrinal, ER stress inhibitor, attenuates kainic acid-induced hippocampal cell death. J Neural Transm (Vienna) 2014; 121: 1233-1243.

34. Ohri SS, Hetman M, Whittemore SR. Restoring endoplasmic reticulum homeostasis improves functional recovery after spinal cord injury. Neurobiol Dis 2013; 58: 29-37.

35. Lentz JJ, Jodelka FM, Hinrich AJ, McCaffrey KE, Farris HE, Spalitta MJ et al. Rescue of hearing and vestibular function by antisense oligonucleotides in a mouse model of human deafness. Nat Med 2013; 19: 345-350.

36. Müller M, Hünerbein Kv, Hoidis S, Smolders JW. A physiological place-frequency map of the cochlea in the CBA/J mouse. Hear Res 2005; 202: 63-73.

37. Han J, Back SH, Hur J, Lin YH, Gildersleeve R, Shan J et al. ER-stress-induced transcriptional regulation increases protein synthesis leading to cell death. Nat Cell Biol 2013; 15: 481-490.

38. Guan BJ, Krokowski D, Majumder M, Schmotzer CL, Kimball SR, Merrick WC et al. Translational control during endoplasmic reticulum stress beyond phosphorylation of the translation initiation factor elF2alpha. J Biol Chem 2014; 289: 12593-12611.

39. Zheng QY, Johnson KR, Erway LC. Assessment of hearing in 80 inbred strains of mice by ABR threshold analyses. Hear Res 1999; 130: 94-107.

40. Han F, Yu H, Tian C, Chen HE, Benedict-Alderfer C, Zheng Y et al. A new mouse mutant of the Cdh23 gene with early-onset hearing loss facilitates evaluation of otoprotection drugs. Pharmacogenomics $\mathrm{J} 2012$.

(i) Cell Death and Disease is an open-access journal published by Nature Publishing Group. This work is licensed under a Creative Commons Attribution 4.0 International License. The images or other third party material in this article are included in the article's Creative Commons license, unless indicated otherwise in the credit line; if the material is not included under the Creative Commons license, users will need to obtain permission from the license holder to reproduce the material. To view a copy of this license, visit http://creativecommons.org/licenses/by/4.0/

(C) The Author(s) 2016 